\title{
Latitudinal and voltinism compensation shape thermal reaction norms for growth rate
}

\author{
LISA N. S. SHAMA, ${ }^{*}+$ MELINA CAMPERO-PAZ, ${ }^{*}$ K. MATHIAS WEGNER, 持MARJAN DE \\ BLOCK* and ROBBY STOKS* \\ ${ }^{*}$ Laboratory of Aquatic Ecology and Evolutionary Biology, University of Leuven, Ch. Deberiotstraat 32, BE-3000 Leuven, \\ Belgium, +Leibniz-Institute for Marine Sciences IFM-GEOMAR, Düsternbrooker Weg 20, 24105 Kiel, Germany, $\ddagger$ Alfred \\ Wegener Institute for Polar and Marine Research, Wadden Sea Station Sylt, 25992 List, Germany, §Universidad Mayor de \\ San Simón, Unidad de Limnología y Recursos Acuáticos, Parque La Torre, Calle Sucre s/n. Casilla 1486, Cochabamba, Bolivia
}

\begin{abstract}
Latitudinal variation in thermal reaction norms of key fitness traits may inform about the response of populations to climate warming, yet their adaptive nature and evolutionary potential are poorly known. We assessed the contribution of quantitative genetic, neutral genetic and environmental effects to thermal reaction norms of growth rate for populations of the damselfly Ischnura elegans. Among populations, reaction norms differed primarily in elevation, suggesting that time constraints associated with shorter growth seasons in univoltine, high-latitude as well as multivoltine, low-latitude populations selected for faster growth rates. Phenotypic divergence among populations is consistent with selection rather than drift as $Q_{\mathrm{ST}}$ was greater than $F_{\mathrm{ST}}$ in all cases. $Q_{\mathrm{ST}}$ estimates increased with experimental temperature and were influenced by genotype by environment interactions. Substantial additive genetic variation for growth rate in all populations suggests that evolution of trait means in different environments is not constrained. Heritability of growth rates was higher at high temperature, driven by increased genetic rather than environmental variance. While environment-specific nonadditive effects also may contribute to heritability differences among temperatures, maternal effects did not play a significant role (where these could be accounted for). Genotype by environment interactions strongly influenced the adaptive potential of populations, and our results suggest the potential for microevolution of thermal reaction norms in each of the studied populations. In summary, the observed latitudinal pattern in growth rates is adaptive and results from a combination of latitudinal and voltinism compensation. Combined with the evolutionary potential of thermal reaction norms, this may affect populations' ability to respond to future climate warming.
\end{abstract}

Keywords: evolutionary potential, genetic correlation, heritability, life history plasticity, $Q_{\mathrm{ST}}$ vs. $F_{\mathrm{ST}}$, time constraints

Received 19 August 2010; revision received 4 May 2011; accepted 10 May 2011

\section{Introduction}

Thermal reaction norms of key life history traits (such as growth rate) play a central role in our understanding of the extent to which populations can persist locally or

Correspondence: Dr Lisa N. S. Shama, Fax:

+49 (0)4651 956 200; E-mail: lisa.shama@awi.de may be replaced by southern populations under anthropogenic temperature changes (Walther et al. 2002; Davis et al. 2005; Parmesan 2006). Two aspects of thermal reaction norms of particular interest in this context are the adaptiveness of their pattern of latitudinal population differentiation (i.e. latitudinal compensation) and their evolutionary potential (Bradshaw \& Holzapfel 2006; Angilletta 2009). 
Species typically show latitudinal compensation whereby growth rates in cold, high-latitude populations equal those of warm, low-latitude populations (Conover \& Present 1990). Both low temperature and strong seasonal time constraints can select for latitudinal compensation and will result in temperature adaptation or countergradient variation, respectively (Conover \& Schultz 1995; Yamahira \& Conover 2002; Yamahira et al. 2007). Temperature adaptation occurs when thermal reaction norms in northern populations are horizontally shifted along a temperature axis towards lower temperatures than southern populations (Levinton 1983; Yamahira et al. 2007). Countergradient variation occurs when genetic and environmental influences on phenotypes are in opposition across an environmental gradient, i.e. faster growing genotypes occur in northern populations (Levins 1969; Conover \& Schultz 1995). Seasonal time constraints have been found to be the driving environmental factor for countergradient variation of growth rates for several taxa (overview in Angilletta 2009). In these cases, growth occurs over the same range of temperatures for both northern and southern populations, but reaction norms differ in elevation such that high-latitude populations grow faster across all temperatures to compensate for the shorter growth season (Conover \& Schultz 1995; Yamahira \& Conover 2002). Although largely overlooked, the degree of voltinism (number of generations per year) at lower latitudes is also associated with seasonal time constraints and can potentially impose stronger time constraints than those of shorter favourable thermal periods at higher latitudes (Roff 1980). Evidence for this is scarce, yet in a recent study, low-latitude, time constrained bivoltine butterflies grew faster than higher latitude, univoltine individuals when reared in a common environment (Nygren et al. 2008).

The study of interpopulation latitudinal variation in thermal reaction norms is considered to be one of the best ways to infer the environmental factors driving adaptive evolution of latitudinal compensation (Yamahira et al. 2007). Yet, this approach can be misleading as stochastic processes such as genetic drift can produce similar patterns (Endler 1977; Merilä \& Crnokrak 2001). Therefore, to explicitly assess the adaptive nature of latitudinal evolution of thermal reaction norms, population-level comparisons of genetic divergence in quantitative traits $\left(Q_{\mathrm{ST}}\right)$ and neutral DNA markers $\left(F_{\mathrm{ST}}\right)$ are needed. Greater divergence in quantitative traits relative to neutral markers (i.e. $Q_{\mathrm{ST}}>F_{\mathrm{ST}}$ ) is indicative of an adaptive pattern in response to directional selection (Merilä \& Crnokrak 2001). Importantly, this conclusion may critically depend upon temperature: $Q_{\mathrm{ST}}$ estimates may be sensitive to the environment and genotype by environment interactions $(\mathrm{G} \times \mathrm{E})$ because the underlying quantitative genetic parameters often vary with the environmental conditions under which they are estimated (Hoffmann \& Merilä 1999; Merilä \& Crnokrak 2001; Palo et al. 2003).

Identifying (adaptive) latitudinal differences in the pattern of thermal reaction norms only reveals past selection events. To predict further thermal adaptation, evolutionary potential and possible genetic constraints need to be evaluated. This has been identified as a major gap in our current knowledge to predict effects of global warming (Angilletta 2009; but see Palo et al. 2003; Yamahira et al. 2007; Nygren et al. 2008). Assessing the potential of thermal reaction norms to evolve is very relevant to understand how species can deal with rapid climate change. Here, the discrimination between microevolutionary (genetic) adaptations and environmentally induced plasticity is paramount to derive correct predictions of a population's adaptive potential (Gienapp et al. 2008).

The combined objectives of this study were to unravel the pattern of latitudinal population differentiation of thermal reaction norms of growth rate, its adaptive nature and evolutionary potential using the damselfly Ischnura elegans (Order: Odonata) as a model system. This ectotherm encounters a wide range of environmental conditions across its distribution (Dijkstra \& Lewington 2006), and selection for local differentiation among populations harbours components of thermal adaptation as well as time constraints, which is reflected in the range of voltinism seen across a latitudinal cline. Our integrated study addresses these issues using two complementary approaches: (i) by quantifying thermal reaction norms of growth rate and their evolutionary potential and (ii) by determining the relative importance of selection vs. drift in shaping patterns of population divergence in growth rate $\left(Q_{\mathrm{ST}}\right.$ vs. $\left.F_{\mathrm{ST}}\right)$, and the extent to which $Q_{\mathrm{ST}}$ estimates may be influenced by the environment and $\mathrm{G} \times \mathrm{E}$.

\section{Methods}

\section{Species and populations}

The damselfly Ischnura elegans (Vander Linden 1820) has a broad latitudinal distribution across Europe, with a range extending from Sweden to Spain (Dijkstra \& Lewington 2006). Populations are univoltine in the north, bivoltine in the centre of its area and multivoltine ( $>2$ generations per year) in the south (Corbet et al. 2006; Dijkstra \& Lewington 2006). Eggs hatch within 2 3 weeks after oviposition followed by an aquatic larval stage ranging from 2 months (multivoltine) up to 11 months (univoltine).

During the peak of the local flight season in 2007, copulating pairs were collected from three populations 
spanning nearly the complete latitudinal range (i.e. $1400 \mathrm{~km}$ ). Specifically, damselflies were collected from a univoltine northern population (Sweden: $55^{\circ} 39^{\prime} \mathrm{N}, 13^{\circ} 32^{\prime} \mathrm{E}$ ), a bivoltine central population (Belgium: $\left.50^{\circ} 50^{\prime} \mathrm{N}, 4^{\circ} 39^{\prime} \mathrm{E}\right)$ and a multivoltine southern population (France: $43^{\circ} 30^{\prime} \mathrm{N}, 4^{\circ} 40^{\prime} \mathrm{E}$ ). Because of the large size of the experiment (more than 3000 experimental units), we chose to rear one population per latitude. Given that four other rearing experiments of this species using replicated populations per latitude consistently found that interpopulation differences in life history traits at given latitudes were much smaller than interlatitude differences (Stoks \& De Block 2011; De Block \& Stoks in preparation; Stoks \& De Block in preparation; Swillen et al. in preparation), we feel confident that any population effects in the current study would truly reflect latitude effects.

Egg clutches were collected by placing mated females on wet filter paper that was used as an oviposition substrate. Filter papers with eggs were kept in aged tap water at $20{ }^{\circ} \mathrm{C}$ until hatching. Prior to larval hatching, a subsample of eggs $(n=10)$ from each clutch was removed from the filter paper and photographed for digital analyses of egg size. Egg size $\left(\mathrm{mm}^{3}\right)$ was estimated as the volume of an ellipsoid. Dimensions of 14 day old eggs from each family were measured to the nearest $0.001 \mathrm{~mm}$ in IMAge-Pro Plus 5.0 (Media Cybernetics, Inc., Bethesda, MD, USA). Mean egg size per family was then used as a covariate in statistical analyses to control for potential egg size-mediated maternal effects (see e.g. Laugen et al. 2002). We produced 30 and 35 full-sibling egg clutches for Sweden and France populations, respectively. Within the Belgium population, 19 males from initial copulating pairs were used for subsequent matings with new field-collected females resulting in 38 paternal half-sibling egg clutches. The use of half-sibling families allowed for better estimates of additive genetic variance corrected for maternal effects (Lynch \& Walsh 1998).

\section{Common garden experiment}

Hatchlings were randomly divided among 21 heated water baths set to one of the three rearing temperatures: 18,21 and $24{ }^{\circ} \mathrm{C}$. This temperature gradient has been shown to generate clear thermal reaction norms in closely related species (Van Doorslaer \& Stoks 2005a,b) and spans the natural temperature regime of the populations of this species during the largest part of the growth season (see also Laugen et al. 2003; Van Doorslaer \& Stoks 2005b). For the first 14 days, hatchlings from each family were held in groups of $c$. 40 individuals in $200 \mathrm{~mL}$ plastic dishes at each of the three temperatures $(n=c$. 120 hatchlings per family in total). On day
15, larvae were assigned individually to plastic cups containing $100 \mathrm{~mL}$ of aged tap water. Ten randomly chosen offspring from each family were reared individually at each of the three temperatures in a full factorial randomized design (total $n=3090$ larvae). Individuals were randomly shuffled among water baths of the same temperature on several occasions during the experiment. Larvae were fed twice daily ad libitum with laboratory-reared brine shrimp nauplii $(334.1 \pm 14.6$ Artemia sp. per feeding). Photoperiod was maintained at $16 \mathrm{~h}$ L:8 $\mathrm{h}$ D throughout the experiment. For logistic reasons, we ended the experiment when larvae reached 65 days of age or the final instar, whichever occurred first. At this point, larvae were towel-dried and weighed to the nearest $0.001 \mathrm{mg}$. In most cases $(87.4 \%)$, larvae were measured at age 65 days. Twelve individuals $(1.3 \%)$ from the Belgium population and 36 individuals (6.3\%) from the Sweden population reached the final instar, whereas 251 individuals (34.6\%) from the France population reached the final instar (mostly from $24{ }^{\circ} \mathrm{C}$ ). Excluding those individuals that reached the final instar did not change the qualitative outcome of statistical analyses; therefore, we retained all individuals to maintain more balanced sample sizes in all treatments. Growth rate was calculated as ln mass/age (see e.g. Johansson et al. 2001; Richter-Boix et al. 2010).

\section{Statistical analyses}

Survival (arcsine-transformed proportions) of larvae was tested by ANOVA using population, temperature and their interaction as fixed factors. Egg size differences among populations were tested by ANOVA using family mean egg sizes. Differences among families in egg size were tested by ANOVA using individual eggs and for each population separately.

Inter- and intrapopulation variation of thermal reaction norms for growth rate were tested using generalized linear mixed models using a Bayesian approach with an animal model implemented in the MCMCGLMm package (Hadfield 2010) in the R statistical environment ( $\mathrm{R}$ Development Core Team 2007). All analyses used proper but weak priors, partitioning observed variance equally between random effects and residuals. Chains were run for 500000 iterations, and posterior distributions were estimated after removing a burn-in of 200000 iterations and taking every 100th sample to optimize chain mixing. Results are expressed as posterior modes from these distributions with $95 \%$ confidence intervals. Convergence of MCMC chains was estimated with the coda package by evaluating autocorrelation between consecutive samples from the posterior distribution. Autocorrelation coefficients of $<0.05$ were considered to represent well-mixed chains. 
In a first approach focussing on among-population variation, the effects of population, experimental temperature, family (nested within population) and egg size on growth rates were analysed using family means. To find the best-fitting model, we sequentially increased model complexity by inclusion of additional factors starting with the random effect family, followed by the fixed effects population, temperature and egg size. We treated population as a fixed factor because they were chosen from latitudes selected a priori based on voltinism (Underwood 1997), and temperature was considered as discrete and not continuous. Model terms were evaluated by the change in deviance information criterion (DIC), assuming that a DIC value change of greater than two represents a significantly better model fit (Spiegelhalter et al. 2002). Fixed effects were additionally tested by evaluating whether parameter estimates from the MCMC samples of the posterior distribution overlapped zero.

In a second approach focusing on within-population variation, genetic/additive variance $\left(V_{\mathrm{G}}\right)$ and heritability $\left(h^{2}\right)$ of growth rates at the three experimental temperatures and genetic correlations between temperatures were calculated using a character-state multivariate animal model treating growth rates at different temperatures as separate traits (Falconer 1952; Via \& Lande 1985). As growth rates at different temperatures were measured in different individuals, we fixed the withinindividual covariance to zero and only estimated genetic correlations $\left(r_{\mathrm{G}}\right)$ among families. Significance of genetic correlations was tested by evaluating whether parameter estimates from the MCMC samples of the posterior distribution overlapped zero (Wilson et al. 2010). An $r_{\mathrm{G}}$ differing from 1 represents a G×E (Windig 1997). As all $r_{\mathrm{G}}$ estimates are confined to a maximum of 1 , we tested significance of $\mathrm{G} \times \mathrm{E}$ by a resampling procedure as advocated by Windig (1997). Specifically, we evaluated the proportion of samples from the posterior distribution of genetic correlations across character states (i.e. growth rates at the different temperatures) overlapping with the minimum estimate of both genetic correlations within a single character state (e.g. $r_{\mathrm{G}}$ between 18 and $21^{\circ} \mathrm{C}$ was compared with lowest estimate obtained for $r_{\mathrm{G}}$ within 18 and $21^{\circ} \mathrm{C}$ ). Theoretically, the within-character-state values should be 1, but sampling from the posterior distribution will provide a sampling error distribution and thereby generate a lower confidence limit, which we used as a cut-off value to determine significance. Empirically, these values ranged from 0.93 to 0.99 .

Heritabilities at each experimental temperature and genetic correlations based on full-sibling analyses were estimated for all populations. As the animal model imposes an expectation of the genetic covariance among individuals based on their additive relationship matrix, these estimates reflect additive (narrow-sense) estimates under the assumption of no nonadditive effects. Given the full-sibling structure and potential maternal effects, these estimates may therefore be upwardly biased. In the Belgium population, heritabilities were calculated using 19 families, i.e. only one family from each sire. Additionally, we used all 38 families to calculate estimates based on half-sibling families, which enabled us to also estimate the maternal contribution by adding 'dam' as an additional random factor in the model.

\section{Population genetic analyses}

Population-level divergence in neutral marker genes (as measured by $F_{\mathrm{ST}}$ ) was determined by multilocus genotyping of 36-40 individuals per population using 10 polymorphic microsatellite loci (see Appendix SI, Supporting information for PCR protocols). Fragments were analysed on a 3130 genetic analyser (Applied Biosystems). Data collection and allele scoring were performed using GeneMapper v3.7. All loci were checked for the presence of null alleles using MICROCHECKER (Van Oosterhout et al. 2004). Of the 10 loci, two contained significant null alleles (I015 and 1053). Therefore, when estimating overall and pairwise population $F_{\mathrm{ST}}$, we used FreeNA (Chapuis \& Estoup 2007) to obtain unbiased $F_{\mathrm{ST}}$ values in the presence of null alleles. All measures of within-population genetic diversity were estimated using eight loci, i.e. without I015 and I053. Genetic diversity of populations was estimated from the mean number of alleles, as well as observed and expected heterozygosity using GENETIX (Belkhir et al. 1998). Deviations from Hardy-Weinberg equilibrium (estimated as $F_{\mathrm{IS}}$ ) were calculated using FSTAT v2.9.3.2 (Goudet 1995).

\section{$\mathrm{Q}_{S T}$ vs. $\mathrm{F}_{S T}$ (quantitative vs. neutral genetic divergence)}

Divergence in quantitative traits can be expressed as (Spitze 1993)

$$
Q_{\mathrm{ST}}=\frac{\sigma_{B}^{2}}{\sigma_{B}^{2}+2 \sigma_{W}^{2}}
$$

where $\sigma_{B}^{2}$ and $\sigma_{W}^{2}$ are the respective between- and within-population components of (additive) genetic variation for the trait under consideration. Analogous to the variance/covariance estimation mentioned above, we also estimated the genetic variance components within and among populations for $Q_{\mathrm{ST}}$ calculations using a character-state approach with an animal model implemented in the MCMCGLMM package (Hadfield 2010) using the animal variance component as a 
measure of within-population variance. Confidence intervals of $Q_{\mathrm{ST}}$ were obtained by sampling parameter estimates from the posterior distribution. Point estimates of $Q_{\mathrm{ST}}$ were calculated as posterior modes with $95 \%$ confidence intervals (Hall et al. 2007). The influence of environment (temperature alone) on $Q_{\mathrm{ST}}$ estimates was assessed by fitting between- and within-population components of genetic variation in a univariate model pooled across all temperatures and comparing the model fit to a multivariate character-state model separating growth rates at each temperature. The effect of G×E (population $\times$ temperature) was then assessed with the multivariate character-state model, fitting interaction terms between growth rates at each temperature and population as random effects. This was done for each pairwise population combination as well as for an overall estimate including all populations.

\section{Results}

Survival differed among populations and temperatures (population $F_{2,296}=20.17$, temperature $F_{2,296}=48.70$, population $\times$ temperature $F_{4,296}=4.68$; all $P \leq 0.001$ ). Survival was highest in Belgium larvae at all temperatures (Fig. S1, Supporting information). In general, survival (\%) decreased with increasing experimental temperature $\left(85.0,75.7\right.$ and 60.9 at 18,21 and $24{ }^{\circ} \mathrm{C}$, respectively). The significant population $\times$ temperature interaction was mainly driven by lower survival of France larvae at $21^{\circ} \mathrm{C}$ (Fig. S1, Supporting information). Mean egg size differed among populations $\left(F_{2,95}=35.88, P<0.001\right)$. Largest mean egg sizes $\left(\mathrm{mm}^{3}\right)$ were from the Belgium population $(0.188 \pm 0.003)$, followed by Sweden $(0.174 \pm 0.004)$, and the smallest eggs were from the France population $(0.151 \pm 0.003)$. Egg size also differed significantly among families within each population ( $P<0.001$ for all populations), but did not show any interaction with temperature on growth rates (egg size $\times$ temperature interaction $F_{2,189}=0.39$; $P=0.676)$, and no significant egg size $\times$ temperature $\times$ population interaction $\left(F_{6,227}=0.17 ; P=0.986\right)$. Mean masses of larvae ( $\mathrm{mg}$ ) at the end of the experiment (65 days) were 8.02 (range: 1.09-34.54), 12.95 (1.43-31.56) and 11.34 (0.94-29.81) for Belgium, France and Sweden, respectively.

\section{Interpopulation variation in thermal reaction norms for growth rate}

The best-fitting model in the interpopulation analysis contained the random factor family as well as the fixed factors population and temperature with the respective interaction term (Table 1). Growth rates were highest for France larvae, intermediate for Sweden larvae and
Table 1 Interpopulation variation of larval growth rates and their thermal sensitivity in Ischnura elegans analysed by generalized linear mixed models and Markov chain Monte Carlo sampling of the posterior distribution. Model fits were evaluated as deviance information criterion (DIC) after sequential inclusion of family, population, temperature and egg size as effects on growth rate

\begin{tabular}{lccc}
\hline & DIC & NDIC & $P$ \\
\hline $\begin{array}{l}\text { (Intercept) } \\
\text { Random effects }\end{array}$ & 1045.47 & - & \\
Family (population) & 1030.86 & -14.61 & \\
Fixed effects & & & \\
Population & 946.00 & -84.86 & $<0.0001$ \\
Temperature & 578.79 & -367.21 & $<0.0001$ \\
Population $\times$ temperature & 387.62 & -191.17 & $<0.0001$ \\
Egg size & 387.61 & -0.01 & 0.889 \\
\hline
\end{tabular}

Note: Family depicts family means, not individuals. Egg size $\left(\mathrm{mm}^{3}\right)$ based on family means using $n=10$ eggs/family. Significance was estimated by the change in DIC. Additionally, significance of fixed effects was tested by sampling the parameter estimates resulting from the posterior distribution, and $P$-values give the proportion of samples smaller than zero.

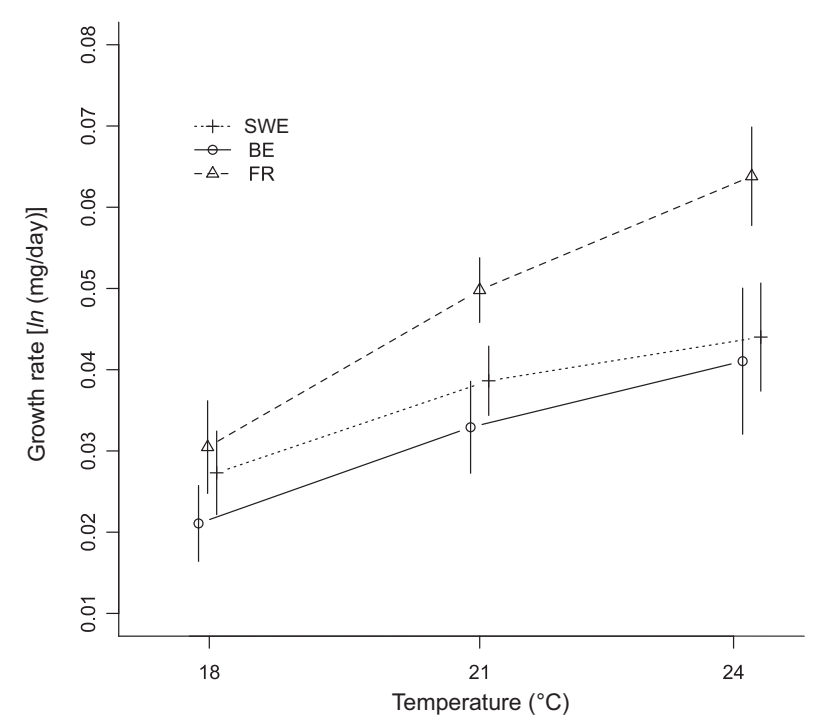

Fig. 1 Population-level thermal reaction norms of larval growth rate for Ischnura elegans from a univoltine northern population (Sweden), a bivoltine central population (Belgium) and a multivoltine southern population (France). Means are given \pm SE.

lowest for Belgium larvae (Fig. 1). All populations showed an increase in growth rate with increasing temperature (temperature main effect; Table 1), and differences among populations were more pronounced at the highest temperature (Fig. 1). Sweden and Belgium larvae reacted similarly to increasing temperatures, whereas France larvae reacted with a much stronger 
increase in growth rate (population $\times$ temperature interaction; Table 1, Fig. 1).

\section{Intrapopulation variation and heritability of growth rates}

The multivariate animal model revealed that populations of Ischnura elegans harboured substantial withinpopulation variation of growth rate at all experimental temperatures. A large proportion of this variation was attributable to genetic effects (null model only fitting intercept DIC $=2164.75$ vs. model containing 'animal' as random effect DIC $=1683.75)$. Full-sibling heritabilities tended to be lower in France (0.33-0.68) when compared with Belgium (0.68-0.80) or Sweden (0.71-0.88; Table 2). Models evaluating heritabilities separately per character state (growth rate per temperature) showed a significantly better fit than those fitting a single value averaged over all temperatures. Changes in DIC favouring temperature-specific heritabilities were 163.6, 224.0 and 243.4 for France, Belgium and Sweden, respectively, indicating that heritability estimates were sensitive to environmental conditions with a tendency to increase with increasing temperature (Table 2). Half-sibling heritabilities were somewhat lower than full-sibling estimates in the Belgium population (Table $2 b$ ), especially at higher temperatures (21 and $24^{\circ} \mathrm{C}$ ), revealing the potential bias introduced by nonadditive genetic effects when estimating heritability based on full-sibling families. However, this bias does not appear to be caused by maternal effects as a model including dam as an additional random effect showed a substantially weaker fit than the model containing only genetic effects (DIC with additive effects: 1683.76 vs. DIC with additive and maternal effects: 1797.81). The lack of maternal effects bias is further supported by low dam variance components ranging from 0.08 (CI: $0.05-0.21$ ) at $18^{\circ} \mathrm{C}$ to 0.11 (CI: $0.06-0.27$ ) at $21^{\circ} \mathrm{C}$ and 0.11 (CI: $0.05-0.29$ ) at $24{ }^{\circ} \mathrm{C}$.

In all three populations, temperature-specific character states of growth rates showed significant positive genetic correlations $\left(r_{\mathrm{G}}\right)$ in most cases (Table 2). It is worth noting that in the Sweden population, $r_{\mathrm{G}}$ did not differ significantly from zero between 18 and $21^{\circ} \mathrm{C}$ nor between 18 and $24{ }^{\circ} \mathrm{C}$, showing that $\mathrm{G} \times \mathrm{E}$ are particularly strong in the northernmost population. More general, all estimates of $r_{\mathrm{G}}$ were significantly lower than within-character-state estimates, also those based on half-siblings in the Belgium population, indicating the presence of $\mathrm{G} \times \mathrm{E}$ in all populations (Table 2).

\section{Neutral genetic variation and differentiation}

The 10 microsatellite loci surveyed were highly polymorphic; a total of 95 different alleles were found in the three I. elegans populations (see Table S1, Supporting information for genetic diversity of loci). Within populations, the mean number of alleles (based on eight loci without null alleles) ranged from 7.000 to 7.875 (Table 3). Observed heterozygosity ranged from 0.606 in the Sweden population to 0.625 in the Belgium population. Only the Sweden population showed a deviation from Hardy-Weinberg equilibrium (HWE) as evidenced by the significant $F_{\mathrm{IS}}$ value observed (Table 3 ). Overall unbiased $F_{\mathrm{ST}}$ was low, but significant $\left(F_{\mathrm{ST}}=0.0096\right.$, 95\% CI: $0.0025-0.0174)$, which also was the case for all pairwise measures of unbiased $F_{\mathrm{ST}}$ (Table 3).

\section{Quantitative vs. neutral genetic differentiation}

Population-level differentiation in the quantitative trait growth rate $\left(Q_{\mathrm{ST}}\right)$ was significantly greater than differentiation at neutral markers $\left(F_{\mathrm{ST}}\right)$ as evidenced by the nonoverlapping 95\% confidence intervals for all $Q_{\mathrm{ST}}$ vs. $F_{\mathrm{ST}}$ comparisons (Fig. 2). Posterior modes for overall $Q_{\text {ST }}$ were 0.43 at $18{ }^{\circ} \mathrm{C}, 0.71$ at $21^{\circ} \mathrm{C}$ and 0.75 at $24{ }^{\circ} \mathrm{C}$. Pairwise population estimates of $Q_{\mathrm{ST}}$ ranged between 0.31 and 0.92 . Models assessing $Q_{\mathrm{ST}}$ values using a multivariate character-state model showed a significantly better fit than univariate models for the overall estimates ( $\triangle \mathrm{DIC}$ in favour of character state: 1789.6), as well as for pairwise estimates $\left(\Delta \mathrm{DIC} \mathrm{CEE}_{\mathrm{BR}}=1116.6\right.$, $\left.\Delta \mathrm{DIC}_{\mathrm{BE}-\mathrm{SW}}=558.1, \Delta \mathrm{DIC}_{\mathrm{FR}-\mathrm{SW}}=1362.2\right)$, indicating that $Q_{\text {ST }}$ estimates are sensitive to environmental conditions. In line with our heritability estimates, quantitative genetic differentiation increased with increasing temperatures (Fig. 3). Fitting population $\times$ temperature interactions further improved the model fit $\left(\Delta \mathrm{DIC}_{\text {overall }}=\right.$ $478.9, \Delta \mathrm{DIC}_{\mathrm{BE}-\mathrm{FR}}=265.1, \quad \Delta \mathrm{DIC}_{\mathrm{BE}-\mathrm{SW}}=99.8, \Delta \mathrm{DIC}_{\mathrm{FR}-}$ $\mathrm{sW}=279.0)$, showing that $Q_{\mathrm{ST}}$ estimates were sensitive not only to temperature but also to $\mathrm{G} \times \mathrm{E}$. This interaction was mainly driven by the France population at higher temperatures where quantitative genetic differentiation greatly exceeded that of $Q_{\mathrm{ST}}$ between the Belgium and Sweden population (Fig. 3).

\section{Discussion}

Our study illustrates the involvement of diversifying natural selection imposed by time constraints associated with latitude and voltinism rather than neutral processes in shaping the latitudinal pattern of larval growth rates in Ischnura elegans, and this is despite high gene flow among populations. Our data suggest the potential for microevolution of thermal reaction norms and underscore the need to evaluate the evolutionary potential of populations under expected higher temperatures to assess their ability to deal in situ with climate warming. 
Table 2 Genetic variance-covariance matrices of intrapopulation variation in larval growth rates of Ischnura elegans analysed by multivariate animal models taking temperature-specific growth rates (character states) as response variables: (a) full-sibling families and (b) Belgium half-sibling families

\begin{tabular}{|c|c|c|c|}
\hline & $18^{\circ} \mathrm{C}$ & $21^{\circ} \mathrm{C}$ & $24{ }^{\circ} \mathrm{C}$ \\
\hline \multicolumn{4}{|c|}{$\begin{array}{l}\text { (a) Full-sibling families } \\
\text { Sweden }\end{array}$} \\
\hline $18^{\circ} \mathrm{C}$ & $\begin{array}{c}V_{\mathrm{A}} 0.38(0.26-0.63) \\
V_{\mathrm{E}} 0.13(0.03-0.22) \\
h^{2} 0.71(0.49-0.92)\end{array}$ & $\begin{array}{l}\mathrm{CoV} 0.09(-0.03 \text { to } 0.23) \\
r_{\mathrm{G}} 0.32^{\text {ns } / * * *}(-0.07 \text { to } 0.65)\end{array}$ & $\begin{array}{l}\mathrm{CoV} 0.16(-0.12 \text { to } 0.35) \\
r_{\mathrm{G}} 0.34^{\text {ns } / * * *}(-0.25 \text { to } 0.60)\end{array}$ \\
\hline $21^{\circ} \mathrm{C}$ & & $\begin{array}{c}V_{\mathrm{A}} 0.23(0.15-0.35) \\
V_{\mathrm{E}} 0.07(0.02-0.13) \\
h^{2} 0.80(0.58-0.95)\end{array}$ & $\begin{array}{l}\mathrm{CoV} 0.23(0.07-0.33) \\
r_{\mathrm{G}} 0.61^{* * * * * *}(0.27-0.83)\end{array}$ \\
\hline $24^{\circ} \mathrm{C}$ & & & $\begin{array}{c}V_{\mathrm{A}} 0.63(0.38-0.84) \\
V_{\mathrm{E}} 0.09(0.04-0.22) \\
h^{2} 0.88(0.68-0.96)\end{array}$ \\
\hline \multicolumn{4}{|l|}{ Belgium } \\
\hline $18^{\circ} \mathrm{C}$ & $\begin{array}{c}V_{\mathrm{A}} 0.35(0.16-0.61) \\
V_{\mathrm{E}} 0.19(0.06-0.30) \\
h^{2} 0.68(0.40-0.90)\end{array}$ & $\begin{array}{l}\operatorname{CoV} 0.19(0.03-0.41) \\
r_{\mathrm{G}} 0.55^{* * * *}(0.15-0.77)\end{array}$ & $\begin{array}{l}\mathrm{CoV} 0.27(0.10-0.48) \\
r_{\mathrm{G}} 0.72^{* * / * *}(0.24-0.86)\end{array}$ \\
\hline $21^{\circ} \mathrm{C}$ & & $\begin{array}{c}V_{\mathrm{A}} 0.50(0.26-0.74) \\
V_{\mathrm{E}} 0.13(0.23-0.46) \\
h^{2} 0.80(0.52-0.94)\end{array}$ & $\begin{array}{l}\mathrm{CoV} 0.27(0.16-0.59) \\
r_{\mathrm{G}} 0.79^{* * * * * *}(0.44-0.91)\end{array}$ \\
\hline $24^{\circ} \mathrm{C}$ & & & $\begin{array}{c}V_{\mathrm{A}} 0.61(0.34-0.80) \\
V_{\mathrm{E}} 0.18(0.05-0.29) \\
h^{2} 0.79(0.54-0.94)\end{array}$ \\
\hline \multicolumn{4}{|l|}{ France } \\
\hline $18^{\circ} \mathrm{C}$ & $\begin{array}{c}V_{\mathrm{A}} 0.63(0.28-0.99) \\
V_{\mathrm{E}} 0.40(0.20-0.62) \\
h^{2} 0.60(0.38-0.83)\end{array}$ & $\begin{array}{l}\mathrm{CoV} 0.16(0.02-0.42) \\
r_{\mathrm{G}} 0.56^{* / * * *}(0.11-0.85)\end{array}$ & $\begin{array}{l}\mathrm{CoV} 0.33(0.06-0.62) \\
r_{\mathrm{G}} 0.68^{* * * * * *}(0.20-0.80)\end{array}$ \\
\hline $21^{\circ} \mathrm{C}$ & & $\begin{array}{c}V_{\mathrm{A}} 0.19(0.09-0.40) \\
V_{\mathrm{E}} 0.37(0.23-0.46) \\
h^{2} 0.33(0.19-0.64)\end{array}$ & $\begin{array}{l}\mathrm{CoV} 0.13(-0.03 \text { to } 0.36) \\
r_{\mathrm{G}} 0.54^{* / * * *}(0.06-0.82)\end{array}$ \\
\hline $24^{\circ} \mathrm{C}$ & & & $\begin{array}{l}V_{\mathrm{A}} 0.70(0.31-1.03) \\
V_{\mathrm{E}} 0.36(0.18-0.62) \\
h^{2} 0.68(0.38-0.88)\end{array}$ \\
\hline \multicolumn{4}{|c|}{ (b) Belgium half-siblings } \\
\hline $18^{\circ} \mathrm{C}$ & $\begin{array}{l}V_{\mathrm{A}} 0.36(0.18-0.54) \\
V_{\mathrm{E}} 0.23(0.13-0.35) \\
h^{2} 0.60(0.37-0.80)\end{array}$ & $\begin{array}{l}\mathrm{CoV} 0.20(0.04-0.38) \\
r_{\mathrm{G}} 0.59^{* * * * * *}(0.20-0.77)\end{array}$ & $\begin{array}{l}\mathrm{CoV} 0.22(0.04-0.39) \\
r_{\mathrm{G}} 0.54^{* * * / * * *}(0.15-0.81)\end{array}$ \\
\hline $21^{\circ} \mathrm{C}$ & & $\begin{array}{l}V_{\mathrm{A}} 0.44(0.27-0.74) \\
V_{\mathrm{E}} 0.21(0.09-0.35) \\
h^{2} 0.66(0.43-0.88)\end{array}$ & $\begin{array}{l}\mathrm{CoV} 0.29(0.14-0.57) \\
r_{\mathrm{G}} 0.74^{* * * / * * *}(0.47-0.90)\end{array}$ \\
\hline $24{ }^{\circ} \mathrm{C}$ & & & $\begin{array}{c}V_{\mathrm{A}} 0.39(0.23-0.76) \\
V_{\mathrm{E}} 0.33(0.15-0.47) \\
h^{2} 0.60(0.36-0.83)\end{array}$ \\
\hline
\end{tabular}

Elements on the diagonal give estimated variance components for $V_{\text {animal }}$ and $V_{\mathrm{E}}$ plus the resulting heritability with $95 \%$ CI. Offdiagonal elements give genetic covariances and genetic correlations $\left(r_{\mathrm{G}}\right)$ between character states. Significance of genetic correlations was tested in two directions: (i) as the proportion of posterior values overlapping zero to demonstrate genetic correlation and (ii) as proportion overlapping $r_{\mathrm{G}}$ estimates for each character state with itself to test for $\mathrm{G} \times \mathrm{E}$ (see Methods).

${ }^{*} P<0.05,{ }^{* *} P<0.01,{ }^{* * *} P>0.001$.

Selection vs. drift in shaping population divergence

Populations of $I$. elegans differed in growth rates across a latitudinal cline. Such geographical differentiation is often the result of spatially varying selection pressures; however, among-population differences also can arise by genetic drift alone (Endler 1977). Hence, only signifi- cantly larger differentiation at quantitative traits $\left(Q_{\mathrm{ST}}\right)$ than at neutral genetic markers $\left(F_{\mathrm{ST}}\right)$ can be interpreted as a sign of diversifying natural selection (Merilä \& Crnokrak 2001; McKay \& Latta 2002; Leinonen et al. 2007). Populations from France, Belgium and Sweden were differentiated from one another at putatively neutral microsatellite markers by about $1 \%$, suggesting 
Table 3 Genetic composition and pairwise measures of genetic differentiation $\left(F_{\mathrm{ST}}\right)$ of three Ischnura elegans populations spanning a latitudinal gradient across Europe. Unbiased estimates of $F_{\mathrm{ST}}$ are shown below the diagonal with significant pairwise comparisons depicted by *. Confidence intervals $(95 \%)$ of pairwise $F_{\mathrm{ST}}$ values are shown above the diagonal

\begin{tabular}{lllllllll}
\hline Population & $n$ & $\mathrm{~A}$ & $H_{\mathrm{o}}$ & $H_{\mathrm{e}}$ & $F_{\mathrm{IS}}$ & Sweden & Belgium & France \\
\hline Sweden & 36 & 7.125 & 0.606 & 0.683 & $0.127^{*}$ & - & $0.0027-0.0185$ & $0.0009-0.0304$ \\
Belgium & 40 & 7.875 & 0.625 & 0.675 & 0.082 & $0.0106^{*}$ & - & $0.0014-0.0108$ \\
France & 40 & 7.000 & 0.619 & 0.668 & 0.086 & $0.0127^{*}$ & $0.0058^{*}$ & - \\
\hline
\end{tabular}

Unbiased estimates of $F_{\mathrm{ST}}$ in the presence of null alleles were calculated based on 10 loci using FreeNA (Chapuis \& Estoup 2007). $n$, Sample sizes; A, mean number of alleles; $H_{\mathrm{o}} / H_{\mathrm{e}}$, observed/expected heterozygosity; $F_{\mathrm{IS}}$, deviations from HWE (averaged over eight loci).

*Significance after Bonferroni correction.

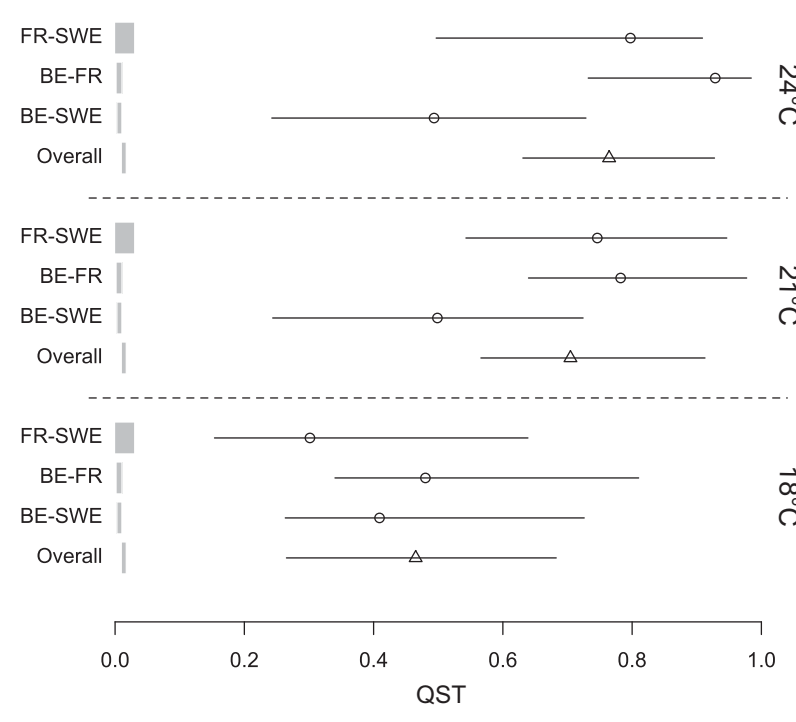

Fig. 2 Genetic differentiation in growth rate $\left(Q_{\mathrm{ST}}\right)$ at three experimental temperatures for Ischnura elegans populations from Sweden (SWE), Belgium (BE) and France (FR). Triangles depict overall $Q_{\mathrm{ST}}$ estimates, and circles represent pairwise population comparisons; $95 \%$ highest posterior densities are shown around the point estimates (posterior modes), and 95\% confidence intervals for differentiation at neutral markers $\left(F_{\mathrm{ST}}\right)$ are shown as grey boxes.

widespread gene flow across Europe. A similar pattern of $F_{\mathrm{ST}}$ across Europe was recently shown for yellow dung flies, with the authors concluding that the lack of population structure probably resulted from high gene flow due to mobility in combination with large population sizes (Demont et al. 2008). Here, we found that $Q_{\mathrm{ST}}$ of growth rate was greater than $F_{\mathrm{ST}}$ in all cases, suggesting a strong effect of selection rather than drift in shaping patterns of $I$. elegans population divergence of this trait. To date, few studies have explicitly assessed the adaptive nature of latitudinal evolution of thermal reaction norms by comparing $Q_{\mathrm{ST}}$ vs. $F_{\mathrm{ST}}$ (but see Palo et al. 2003; Demont et al. 2008). Our findings are in agreement with these studies, as well as the majority of $Q_{\mathrm{ST}}$ vs. $F_{\mathrm{ST}}$ research that has shown that selection rather than genetic drift is the more likely causal explanation

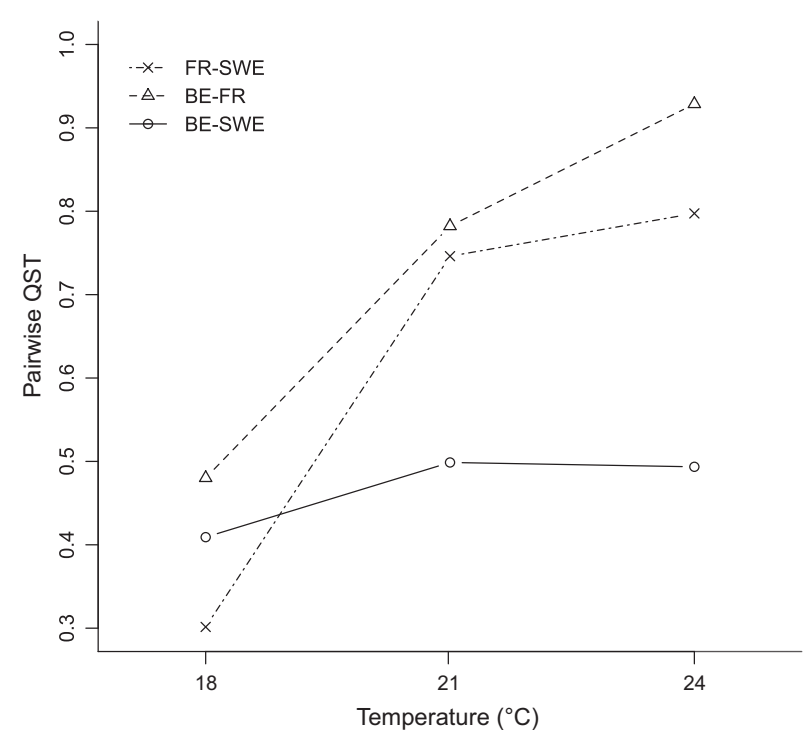

Fig. 3 Thermal reaction norms of pairwise $Q_{\mathrm{ST}}$ estimates (posterior modes) showing an increase in adaptive differentiation with increasing temperature and genotype by environment interactions.

for population divergence in quantitative traits (Merilä \& Crnokrak 2001; McKay \& Latta 2002; Leinonen et al. 2007; Richter-Boix et al. 2010). Moreover, our results contribute to the growing body of evidence, indicating that in some systems, adaptive divergence of populations can be maintained by natural selection in spite of high gene flow (see e.g. Endler 1977; Garant et al. 2007).

We also found that overall $Q_{\mathrm{ST}}$ differed among experimental temperatures, lending support to the hypothesis that $Q_{\mathrm{ST}}$ estimates are sensitive to environmental conditions (Merilä \& Crnokrak 2001; Palo et al. 2003). The observed increase in overall $Q_{\mathrm{ST}}$ with increasing temperature is probably linked to the underlying higher pairwise estimates involving the France population. Thermal reaction norms of $Q_{\mathrm{ST}}$ show nonparallel slopes, the steepest of which (France-Sweden) being mostly 
driven by high growth rates at $24{ }^{\circ} \mathrm{C}$ in the France population. This suggests that our $Q_{\mathrm{ST}}$ estimates may be sensitive not only to environment but also to $\mathrm{G} \times \mathrm{E}$, which can complicate evolutionary inferences (Palo et al. 2003). Note that the increase in $Q_{\mathrm{ST}}$ with temperature also could be driven by bias stemming from population-specific nonadditive effects (Merilä \& Crnokrak 2001). Life history traits such as growth rate are known to harbour substantial nonadditive genetic effects compared with, for example, morphological traits (Roff 1997). Although a half-sibling breeding design cannot partition out dominance or epistatic effects, at least in the Belgium population where we could estimate maternal effects, these did not have a significant influence on genetic variance. Note also that the order of population mean growth rates (Belgium $<$ Sweden $<$ France) is opposite to the order for population mean egg size, indicating that egg size-mediated maternal effects are unlikely to contribute to population divergence in growth rates.

Survival differed among populations and temperatures; however, these differences are likely not driving latitude or $Q_{\text {ST }}$ patterns. Higher survival of Belgium larvae at all temperatures may be due to their overall lower growth rates: high growth rate has been shown to be traded off against other functions including energy storage in damselfly larvae (Stoks et al. 2006a). Accordingly, lower survival at higher temperatures seen in all populations is probably the result of higher (relative) growth rates. Furthermore, a temperature-mediated growth increase was most pronounced in France larvae between 18 and $21^{\circ} \mathrm{C}$ and matches the marked reduction in survival under the same conditions (giving rise to the population by temperature interaction for survival). Differential survival is also unlikely to bias patterns in our $Q_{\mathrm{ST}}$ estimates. For example, at $21^{\circ} \mathrm{C}$ survival was highest in Belgium larvae and equally low in France and Sweden larvae, yet the pairwise $Q_{\mathrm{ST}}$ estimate for Belgium-France was much higher than that of Belgium-Sweden. Moreover, the former was similar to the $Q_{\text {ST }}$ estimate for Sweden-France. Also, at $24^{\circ} \mathrm{C}$, the pattern in $Q_{\mathrm{ST}}$ estimates does not seem to reflect the pattern in survival. While survival was equally low for all three latitudes at $24{ }^{\circ} \mathrm{C}$, pairwise $Q_{\text {ST }}$ estimates differed widely at this temperature. Furthermore, the $Q_{\mathrm{ST}}$ estimate for Belgium-Sweden was essentially the same at 21 and $24{ }^{\circ} \mathrm{C}$, while at both latitudes, survival decreased considerably from 21 to $24^{\circ} \mathrm{C}$.

\section{Latitudinal variation in thermal reaction norms of growth rate}

Thermal reaction norms among populations differed primarily in elevation, suggesting that time constraints associated with seasonality rather than temperature is the main environmental factor shaping growth rates in the wild. Time constraints have been shown to be an important factor causing accelerated growth rates in damselflies (e.g. De Block \& Stoks 2004, 2005; Stoks et al. 2006b). Interestingly, the nature of the time constraint, i.e. the underlying reason for shorter larval growth seasons, differs in function with latitude: multivoltinism at low latitude (France) and inhospitable climate conditions at high latitude (Sweden). Higher growth rates of the France population relative to Sweden indicate that, in our case, time constraints imposed by multivoltinism are stronger than those imposed by latitude. Additionally, there is also some evidence for thermal adaptation playing a role as indicated by the steeper thermal reaction norm of the France population. In other words, we observe a mixed strategy where reaction norms are shifted both vertically and horizontally relative to the importance of seasonality vs. temperature (sensu Yamahira et al. 2007). Note that the studied temperature range, while ecologically relevant, was rather narrow (only $6^{\circ} \mathrm{C}$ ) and that studying thermal reaction norms across a broader temperature range may likely identify a more important role of variation in the temperature dependence of growth (Kingsolver et al. 2004).

The identified latitudinal growth rate pattern is therefore a combination of latitudinal and voltinism compensation. Several studies have demonstrated growth rate adaptation to seasonality in high-latitude populations (overview in Angilletta 2009), but few have shown adaptation to voltinism, despite its intuitive appeal (but see Nygren et al. 2008; Ragland \& Kingsolver 2007 for development rate; Karl et al. 2008 for voltinism compensation across an altitudinal gradient). Yet, none so far considered their combination. As pure patterns of latitudinal compensation can no longer be expected when populations of mixed voltinism are compared and changes in voltinism are widely documented along latitudinal gradients (Corbet et al. 2006; Altermatt 2010), such mixed patterns are likely to be very common. Rather than a monotonous increase in growth rates with increasing latitude, a U-shaped or a more complex saw-tooth pattern reflecting abrupt changes in voltinism along a latitudinal transect may then be expected as documented in our study. This recalls the similar pattern for body size predicted by Roff (1980) based on the same combination of latitudinal and voltinism compensation, and which has been shown in some studies (Johansson 2003; De Block et al. 2008; Nygren et al. 2008). Note, however, that Roff (1980) did not explicitly consider growth rate and assumed the size pattern to be proximately driven by development rate, while growth rate may vary independently from development rate (e.g. Johansson \& Rowe 1999; 
Johansson et al. 2001), and potentially compensates for changes in development time (Abrams et al. 1996).

The latitudinal pattern in growth rate shown here has relevance for northward range shifts under global warming, which have been shown to be particularly strong in odonates (Hickling et al. 2006). As growth rate is a key trait linked to fitness and often used as a metric to predict competitive outcome (Lindgren \& Laurila 2010), our results suggest (all else being equal) that France animals that invade Belgium will outcompete the local populations, while this may not be the case when Belgium animals invade Sweden. Admittedly, this prediction critically depends on the existence of tradeoffs between growth rate and other fitness-related traits (reviewed by Angilletta et al. 2003), yet it provides a testable hypothesis. It is worth noting that a recent study showed that northern, fast-growing tadpoles outcompeted southern tadpoles in a competition experiment (Lindgren \& Laurila 2010). Such competitive superiority of fast-growing genotypes has the potential to modify not only intraspecific but also interspecific interactions with possible cascading effects on the ecosystem if the climate changes.

The adaptiveness of the here-reported latitudinal pattern in growth rate needs to be considered in the larger context of overall life history variation across latitudes, where besides growth rate, age and mass at emergence are key determinants of adult fitness. Higher growth rates of France larvae are associated with much higher development rates, hence shorter development times, and the lowest mass at emergence (Stoks \& De Block 2011; Swillen et al. in preparation). This is consistent with the compound interest hypothesis stating that in populations with relatively short generation times as compared to season length, fitness will be maximized by increasing the number of generations, even at the expense of being small (Partridge \& French 1996; Fischer \& Fiedler 2002). In contrast, Sweden larvae have the longest development times and highest mass at emergence, while Belgium larvae show intermediate values for both (Stoks \& De Block 2011; Swillen et al. in preparation). Conditions for growth in Sweden do not allow an extra generation, and in such univoltine populations, selection for large size at maturity to maximize adult fitness should be particularly strong (Partridge \& French 1996; Fischer \& Fiedler 2002).

\section{Evolutionary potential of thermal reaction norms of growth rate}

Each of the populations of I. elegans showed heritable (additive) genetic variation for growth rate, indicating that adaptive evolution of thermal reaction norms to environmental change does not seem to be constrained by the amount of standing genetic variation. Comparable results have been found in latitudinal populations of several taxa (Palo et al. 2003; Blanckenhorn \& Demont 2004; Van Doorslaer \& Stoks 2005b; Yamahira et al. 2007; Nygren et al. 2008). Heritabilities of growth rate also were sensitive to environmental conditions with a pattern of higher heritability at higher temperature. Stressful, unfavourable and/or novel conditions are known to contribute to changes in heritability across environments (reviewed by Hoffmann \& Merilä 1999). Mechanisms include changes in additive genetic variance, environmental variance, nonadditive effects including maternal effects, and G×E (Charmantier \& Garant 2005; Kruuk et al. 2008). In our study, changes in heritability are more influenced by higher (additive) genetic variances at $24{ }^{\circ} \mathrm{C}$ than by changing environmental variances (which were similar among temperatures for each population). Note that heritabilities based on half-sibling families in the Belgium population were lower than those estimated from full-siblings and were similar at each temperature, suggesting that changes in full-sibling genetic variances across temperatures also include some form of environment-specific nonadditive effect. Although we could rule out maternal effects in the Belgium population, these still may be present in the Sweden and France populations.

Changes in heritability across experimental temperatures were influenced by $\mathrm{G} \times \mathrm{E}$. Particularly in the northernmost population (Sweden), low (nonsignificant) genetic correlations between temperatures indicate that the underlying genetic architecture differs at high vs. low temperature (Via \& Lande 1985; Hoffmann \& Merilä 1999). Moreover, in all populations, significant $G \times E$ (genetic correlations less than 1) suggest that thermal reaction norms for growth rate have the potential to evolve (Via 1993; Charmantier \& Garant 2005), although there may be differences among populations in the magnitude of $\mathrm{G} \times \mathrm{E}$, i.e. some populations are more plastic than others or have a higher heritability of plasticity (Roff 1997; Visser 2008).

Adaptive plasticity of thermal reaction norms in response to changing environmental temperatures could allow populations to rapidly track the moving selective optimum and result in partial or full maintenance of fitness in the new environment (Gienapp et al. 2008). Our results are in contrast with recent studies of fish (Oryzias sp.) that found that within-population reaction norms were more or less parallel across temperatures, with the authors concluding that this represented a constraint in the evolution of latitudinal compensation (Yamahira et al. 2007). Here, the adaptive pattern of latitudinal compensation in growth rate that results from a combination of latitudinal and voltinism compensation has the potential to evolve. Evolution of 
growth rate in response to climate warming in local populations may buffer against immigration of southern genotypes with currently higher growth rates. Our study illustrates the value of an integrated approach where an evaluation of the adaptiveness of current latitudinal patterns (that reveal past selection events) is combined with identifying the potential for further evolution of thermal reaction norms in situ. Especially, the latter information is rarely available yet crucial to predict effects of climate change (Angilletta 2009).

\section{Acknowledgements}

We are very grateful to Rony Van Aerschot, Bart Hellemans and Ine Swillen (K.U. Leuven) for help with the experiment; Tom Gosden and Erik Svensson (Univ. Lund) for help in collecting Sweden eggs; Patrick Grillas and Damian Cohez (Tour du Valet) and Dirk Mikolajewski (Univ. Sheffield) for help in collecting France eggs; Rosa Ana Sanchez (Univ. Vigo) and Hans Van Gossum (Univ. Antwerp) for DNA extractions; Maren Wellenreuther (Univ. Lund) for help with the microsatellite primers; and David Hall (Univ. Umea) for help with the $\mathrm{R}$ scripts for $Q_{\mathrm{ST}}$ analyses. Many thanks to Katja Räsänen and Jukka Jokela for helpful discussions and comments on an earlier version of the manuscript. The manuscript was further improved by comments made by Joel Kingsolver, Jessica Higgins and three anonymous reviewers. The study was funded by a Swiss National Science Foundation postdoctoral fellowship to LNSS and from research grants of the Fund for Scientific Research-Flanders and the KU Leuven Research Foundation to RS.

\section{References}

Abrams PA, Leimar O, Nylin S, Wiklund C (1996) The effect of flexible growth rates on optimal sizes and development times in a seasonal environment. American Naturalist, 147, 381-395.

Altermatt F (2010) Climatic warming increases voltinism in European butterflies and moths. Proceedings of the Royal Society of London B, 277, 1281-1287.

Angilletta MJ (2009) Thermal Adaptation: A Theoretical and Empirical Synthesis. Oxford University Press Inc., New York.

Angilletta MJ, Wilson RS, Navas CA, James RS (2003) Tradeoffs and the evolution of thermal reaction norms. Trends in Ecology and Evolution, 18, 234-240.

Belkhir K, Borsa P, Goudet J, Chikhi L, Bonhome F (1998) GENETIX, logiciel sous Windows pour la genetique des populations. CNRS UPR 9060Universite de Montpellier II, France.

Blanckenhorn WU, Demont M (2004) Bergmann and converse Bergmann latitudinal clines in arthropods: two ends of a continuum? Integrative and Comparative Biology, 44, 413-424.

Bradshaw WE, Holzapfel CM (2006) Evolutionary response to rapid climate change. Science, 312, 1477-1478.

Chapuis MP, Estoup A (2007) Microsatellite null alleles and estimation of population differentiation. Molecular Biology and Evolution, 24, 621-631.
Charmantier A, Garant D (2005) Environmental quality and evolutionary potential: lessons from wild populations. Proceedings of the Royal Society of London B, 272, 1415-1425.

Conover DO, Present TMC (1990) Countergradient variation in growth rate: compensation for length of the growing season among Atlantic silversides from different latitudes. Oecologia, 83, 316-324.

Conover DO, Schultz ET (1995) Phenotypic similarity and the evolutionary significance of countergradient variation. Trends in Ecology and Evolution, 10, 248-253.

Corbet PS, Suhling F, Söndgerath D (2006) Voltinism of Odonata: a review. International Journal of Odonatology, 9, 1-44.

Davis MB, Shaw RG, Etterson JR (2005) Evolutionary responses to changing climate. Ecology, 86, 1704-1714.

De Block M, Stoks R (2004) Life-history variation in relation to time constraints in a damselfly. Oecologia, 140, 68-75.

De Block M, Stoks R (2005) Fitness effects from egg to reproduction: bridging the life history transition. Ecology, 86, 185-197.

De Block M, Slos S, Johansson F, Stoks R (2008) Integrating life history and physiology to understand latitudinal size variation in a damselfly. Ecography, 31, 115-123.

Demont M, Blanckenhorn WU, Hosken DJ, Garner TWJ (2008) Molecular and quantitative genetic differentiation across Europe in yellow dung flies. Journal of Evolutionary Biology, 21, 1492-1503.

Dijkstra KDB, Lewington R (2006) Field Guide to the Dragonflies of Britain and Europe. British Wildlife Publishing, Gilingham.

Endler JA (1977) Geographic Variation, Speciation and Clines. Princeton University Press, Princeton.

Falconer DS (1952) The problem of environment and selection. American Naturalist, 86, 283-298.

Fischer K, Fiedler K (2002) Reaction norms for age and size at maturity in response to temperature: a test of the compound interest hypothesis. Evolutionary Ecology, 16, 333-349.

Garant D, Forde SE, Hendry AP (2007) The multifarious effects of dispersal and gene flow. Functional Ecology, 21, 434-443.

Gienapp P, Teplitsky C, Alho JS, Mills JA, Merilä J (2008) Climate change and evolution: disentangling environmental and genetic responses. Molecular Ecology, 17, 167-178.

Goudet J (1995) FSTAT (vers.2.9.3.2): a computer program to calculate F-statistics. Journal of Heredity, 86, 485-486.

Hadfield J (2010) MCMC methods for Multiresponse Generalised Linear Mixed Models: The MCMCglmm R Package. Journal of Statistical Software, 33, 1-22.

Hall D, Luquez V, Garcia VM, St Onge KR, Jansson S, Ingvarsson PK (2007) Adaptive population differentiation in phenology across a latitudinal gradient in European Aspen (Populus tremula, L.): a comparison of neutral markers, candidate genes and phenotypic traits. Evolution, 61, 28492860.

Hickling R, Roy DB, Hill JK, Fox R, Thomas CD (2006) The distributions of a wide range of taxonomic groups are expanding polewards. Global Change Biology, 12, 1-6.

Hoffmann AA, Merilä J (1999) Heritable variation and evolution under favourable and unfavourable conditions. Trends in Ecology and Evolution, 14, 96-101.

Johansson F (2003) Latitudinal shift in body size of Enallagma cyathigerum (Odonata). Journal of Biogeography, 30, 29-34. 
Johansson F, Rowe L (1999) Life history and behavioural responses to time constraints in a damselfly. Ecology, 80, 1242-1252.

Johansson F, Stoks R, Rowe L, De Block M (2001) Life history plasticity in a damselfly: effects of combined time and biotic constraints. Ecology, 82, 1857-1869.

Karl I, Janowitz SA, Fischer K (2008) Altitudinal life-history variation and thermal adaptation in the copper butterfly Lycaena tityrus. Oikos, 117, 778-788.

Kingsolver JG, Izem R, Ragland GJ (2004) Plasticity of size and growth in fluctuating thermal environments: comparing reaction norms and performance curves. Integrative and Comparative Biology, 44, 450-460.

Kruuk LEB, Slate J, Wilson AJ (2008) New answers for old questions: the evolutionary quantitative genetics of wild animal populations. Annual Review of Ecology, Evolution and Systematics, 39, 525-548.

Laugen AT, Laurila A, Merilä J (2002) Maternal and genetic contributions to geographical variation in Rana temporaria larval life-history traits. Biological Journal of the Linnaean Society, 76, 61-70.

Laugen AT, Laurila A, Räsänen K, Merilä J (2003) Latitudinal countergradient variation in the common frog (Rana temporaria) development rates - evidence for local adaptation. Journal of Evolutionary Biology, 16, 996-1005.

Leinonen T, O’Hara RB, Cano JM, Merilä J (2007) Comparative studies of quantitative trait and neutral marker divergence: a meta-analysis. Journal of Evolutionary Biology, 21, 1-17.

Levins R (1969) Thermal acclimation and heat resistance in Drosophila species. American Naturalist, 103, 483-499.

Levinton JS (1983) The latitudinal compensation hypothesis: growth data and a model of latitudinal growth differentiation based upon energy budgets. I. Interspecific comparison of Ophryotrocha pueriles (Polychaeta: Dorvilleidae). Biological Bulletin, 165, 686-698.

Lindgren B, Laurila A (2010) Are high-latitude individuals superior competitors? A test with Rana temporaria tadpoles. Evolutionary Ecology, 24, 115-131.

Lynch M, Walsh B (1998) Genetics and Analysis of Quantitative Traits. Sinauer Associates Inc., MA, USA.

McKay JK, Latta RG (2002) Adaptive population divergence: markers, QTL and traits. Trends in Ecology and Evolution, 17, 285-291.

Merilä J, Crnokrak P (2001) Comparison of genetic differentiation at marker loci and quantitative traits. Journal of Evolutionary Biology, 14, 892-903.

Nygren GH, Bergström A, Nylin S (2008) Latitudinal body size clines in the butterfly Polyommatus icarus are shaped by gene-environment interactions. Journal of Insect Science, 8, 113.

Palo JU, O'Hara BO, Laugen AT, Laurila A, Primmers CR, Merilä J (2003) Latitudinal divergence of common frog (Rana temporaria) life history traits by natural selection: evidence from a comparison of molecular and quantitative genetic data. Molecular Ecology, 12, 1963-1978.

Parmesan C (2006) Ecological and evolutionary responses to recent climate change. Annual Review of Ecology and Systematics, 37, 637-669.

Partridge L, French V (1996) Thermal evolution of ectotherm body size: why get big in the cold?. In:Animals and Temperature: Phenotypic and Evolutionary Adaptation (eds
Johnston IA, Bennett AF). pp. 265-292, Cambridge University Press, Cambridge.

$\mathrm{R}$ Development Core Team (2007) R: A Language and Environment for Statistical Computing. $\mathrm{R}$ Foundation for Statistical Computing, Vienna.

Ragland GJ, Kingsolver JG (2007) Influence of seasonal timing on thermal ecology and thermal reaction norm evolution in Wyeomyia smithii. Journal of Evolutionary Biology, 20, 21442153.

Richter-Boix A, Teplitsky C, Rogell B, Laurila A (2010) Local selection modifies phenotypic divergence among Rana temporaria populations in the presence of gene flow. Molecular Ecology, 19, 716-731.

Roff DA (1980) Optimizing development time in a seasonal environment: the "ups and downs" of clinal variation. Oecologia, 45, 202-208.

Roff DA (1997) Evolutionary Quantitative Genetics. Chapman and Hall, New York.

Spiegelhalter D, Best N, Carlin B, Der Van Linde A (2002) Bayesian measures of model complexity and fit. Journal of the Royal Statistical Society: Series B (Statistical Methodology), 64, 583-639.

Spitze K (1993) Population structure in Daphnia obtusa: quantitative genetic and allozymic variation. Genetics, 135, 367-374.

Stoks R, De Block M (2011) Rapid growth reduces cold resistance: evidence from latitudinal variation in growth rate, cold resistance and stress proteins. PLoS ONE, 6, e16935.

Stoks R, De Block M, McPeek MA (2006a) Physiological costs of compensatory growth in a damselfly. Ecology, 87, 15661574.

Stoks R, De Block M, Slos S, Van Doorslaer W, Rolff J (2006b) Time constraints mediate predator-induced plasticity in immune function, condition, and life history. Ecology, 87, 809-815.

Underwood AJ (1997) Experiments in Ecology: Their Logical Design and Interpretation Using Analysis of Variance. Cambridge University Press, Oxford.

Van Doorslaer W, Stoks R (2005a) Growth rate plasticity to temperature in two damselfly species differing in latitude: contributions of behaviour and physiology. Oikos, 111, 599605.

Van Doorslaer W, Stoks R (2005b) Thermal reaction norms in two Coenagrion damselfly species: contrasting embryonic and larval life-history traits. Freshwater Biology, 50, 19821990.

Van Oosterhout C, Hutchinson WF, Wills DPM, Shipley P (2004) Micro-checker: software for identifying and correcting genotyping errors in microsatellite data. Molecular Ecology Notes, 4, 535-538.

Via S (1993) Adaptive phenotypic plasticity - target or byproduct of selection in a variable environment. American Naturalist, 142, 352-365.

Via S, Lande R (1985) Genotype-environment interaction and the evolution of phenotypic plasticity. Evolution, 39, 505-522.

Visser ME (2008) Keeping up with a warming world: assessing the rate of adaptation to climate change. Proceedings of the Royal Society of London B, 275, 649-659.

Walther GR, Post E, Convey P et al. (2002) Ecological responses to recent climate change. Nature, 416, 389-395. 
ADAPTIVE POTENTIAL OF THERMAL REACTION NORMS 2941

Wilson A, Réale D, Clements M et al. (2010) An ecologist's guide to the animal model. Journal of Animal Ecology, 79, 1326.

Windig JJ (1997) The calculation and significance testing of genetic correlations across environments. Journal of Evolutionary Biology, 10, 853-874.

Yamahira K, Conover DO (2002) Intra- vs. interspecific latitudinal variation in growth: adaptation to temperature or seasonality? Ecology, 83, 1252-1262.

Yamahira K, Kawajiiri M, Takeshi K, Irie T (2007) Inter- and intrapopulation variation in thermal reaction norms for growth rate: evolution of latitudinal compensation in ectotherms with a genetic constraint. Evolution, 61, 1577-1589.

L.N.S.S. is an evolutionary ecologist with particular interests in genetic responses to environmental change. M.C.P. is an ecologist with interests in physiological and behavioral strategies of organisms to cope with abiotic and biotic stress. K.M.W. is an evolutionary ecologist now mainly interested in ecosystem consequences and evolutionary responses to infection by opportunistic pathogens. M.D.B. and R.S. are evolutionary ecologists working on adaptation and plasticity to anthropogenic and natural stressors.

\section{Data accessibility}

Data deposited at Dryad: doi:10.5061/dryad.hs727.

\section{Supporting information}

Additional supporting information may be found in the online version of this article.

Fig. S1 Survival of I. elegans larvae from three populations (Sweden, Belgium, France) exposed to three experimental rearing temperatures.

Table S1 Genetic diversity of the 10 microsatellite loci used to genotype Ischnura elegans from three populations across a latitudinal gradient.

Appendix SI Polymerase chain reaction (PCR) protocols for 10 microsatellite loci amplified using DNA extracted from I. elegans.

Please note: Wiley-Blackwell are not responsible for the content or functionality of any supporting information supplied by the authors. Any queries (other than missing material) should be directed to the corresponding author for the article. 